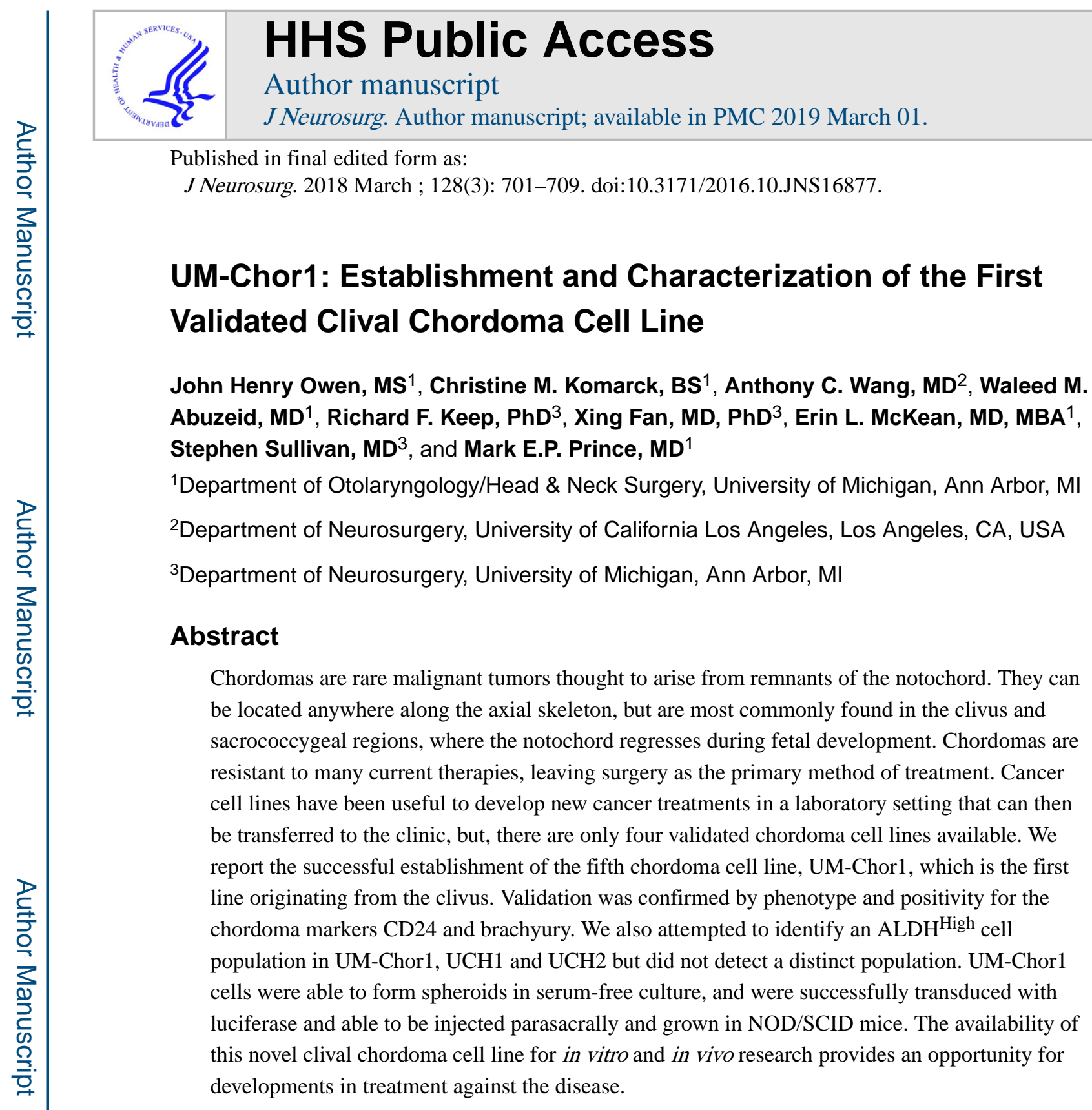

\title{
Introduction
}

Chordoma is a slow-growing malignancy originating from the bone along the neuraxis. A rare cancer, chordomas occur in approximately 1:1,000,000, leading to roughly 300 new cases in the United States each year ${ }^{9}, 19$. Resistance to conventional chemo and radiotherapies is high in the disease and surgery remains the most common form of treatment ${ }^{14,31}$. The location and size of chordoma tissue and infiltration around the central nervous system makes surgery difficult and, as a result, recurrence is high ${ }^{4}$. Development of potent anticancer agents against chordoma has suffered from a lack of immortalized cell lines to study in the laboratory.

Corresponding Author: Dr. Mark E.P. Prince, 1500 E. Medical Center Dr., 1903 Taubman Center, SPC 5312, Ann Arbor, MI 48109, Phone: (734) 647-6498, Fax: (734) 936-8052, Requests for Reprints: please contact corresponding author. 
Classical chordoma is characterized histologically as a lobulated tumor separated by fibrous septa. Individual cells tend to be highly vacuolated, displaying what is referred to as a physaliferous appearance. Chordoma cells express Pan-cytokeratin, EMA, S100 and vimentin, and have a deficiency in PTEN $^{8,37}$. The definitive diagnostic marker for chordoma is brachyury, a nuclear transcription factor involved in defining the midline of a bilateral organism ${ }^{3}, 18,28$. Germ line duplication of the chromosomal region containing the brachyury gene confers chordoma susceptibility ${ }^{21,40}$.

Chordoma cells share characteristics of cancer stem cells, including the ability to self-renew and differentiate. Furthermore, the resistance to chemotherapy exhibited by many chordomas is also a property of cancer stem cells $\mathrm{s}^{1,39}$. Whether chordomas contain a subpopulation of stem-like cells has yet to be thoroughly investigated. A 2012 study showed a self-renewal potential in chordoma cells isolated for stem-cell markers CD15 and CD1332. ALDH1 has been shown to be a marker for cancer stem cells in many cancer types, and the isolation of a sub-population of $\mathrm{ALDH}^{\mathrm{High}}$ cells in chordomas is currently being attempted by other groups ${ }^{10,16,24}$.

Despite an increase in chordoma awareness and research after the creation of the Chordoma Foundation in 2007, understanding the molecular mechanisms of tumorigenesis and potential therapeutic targets remains a constant goal. Creation of new chordoma cell lines is a first step to achieving rigorous in vitro testing and characterization of the disease. At the time of creation of UM-Chor1, only four chordoma cell lines were available to researchers worldwide ${ }^{17,20,33}$. All four were isolated from sacral growths. We present the first clival chordoma cell line to assist in characterization of the disease as well as developing new treatment options.

\section{Materials and Methods}

Approvals for the collection of cancer specimens and for use of the animal model were obtained through the appropriate review boards. The University of Michigan's Guide for the Care and Use of Laboratory Institutional Animals was followed.

\section{Patients}

Patients were recruited from the Department of Neurosurgery at the University of Michigan and asked to sign an Institutional Review Board approved informed consent to study their tissue, including permission to establish a permanent cell line.

\section{Previously Established Chordoma Cell Lines}

Established cell lines UCH1 and UCH2 were generously provided by the Chordoma Foundation, of Durham, North Carolina.

\section{Preparation and Digestion of Tissue}

Primary tumor tissue was transported from the operating room to the lab and was washed extensively in Hank's balanced salt solution containing penicillin, streptomycin, and amphotericin B. The tissue was then minced by scalpel blade and digested in DMEM/F12 
(Gibco) with 1X collagenase/hyaluronidase (Stem Cell Technologies). After two hours of digestion at $37^{\circ} \mathrm{C}$, the mixture was strained through a 40 um sieve and the cells were placed in a culture flask. Remaining tumor pieces were placed in a separate flask for further observation of growth.

\section{Cell Line Establishment}

Cells were cultured in 20\% fetal bovine serum (FBS) 4:1 IMDM:RPMI (Gibco) containing penicillin, streptomycin, non-essential amino acids, and amphotericin B and grown in Collagen I coated flasks (BD Biosciences). Supernatants were tested for mycoplasma using Myco Alert Mycoplasma Testing Kit (Lonza). Once growth without contamination was confirmed, cells were grown in 10\% FBS media in tissue-treated flasks. The sample was genotyped and named UM-Chor1 after sixty successful doublings, which occurred roughly after twenty-five passages or seventy-eight weeks.

\section{Genomic DNA Purification for Genotyping}

Cells were harvested and washed in PBS, then frozen at $-80^{\circ} \mathrm{C}$. The thawed cell pellets were re-suspended in $600 \mathrm{uL}$ of Promega Nuclei Lysis Solution (Promega) for one hour at $55^{\circ} \mathrm{C}$, then allowed to cool to room temperature. $200 \mathrm{uL}$ of Promega Protein Precipitation Solution (Promega) was added to each sample on ice for five minutes before being centrifuged at 13,000 RPM for two minutes. Supernatant was transferred to a tube containing $600 \mathrm{uL}$ of isopropanol and centrifuged at 13,000 RPM for one minute. Supernatant was aspirated and the DNA pellet washed in $200 \mathrm{uL}$ of $70 \%$ ethanol and re-suspended in $50 \mathrm{uL}$ of nucleasefree water.

\section{Analysis of Genetic Loci}

DNA samples were diluted to $0.10 \mathrm{ng} / \mathrm{L}$ and were analyzed at the University of Michigan DNA Sequencing Core using the Profiler Plus PCR Amplification Kit (Invitrogen) in accord with the manufacturer's protocol. The 10 loci D3S1358, D5S818, D7S820, D8S1179, D13S317, D18S51, D21S11, FGA, vWA, and AMEL were analyzed and compared with ladder control samples.

\section{Flow Cytometry}

NCAM and FSP expression were detected using primary antibodies (BD Pharmingen \#559043; Abcam \#11333) and fluorophore-conjugated secondary antibodies (BD Pharmingen \#550874; eBioscience \#12-5790-81). CD24 expression was detected using a fluorophore-conjugated primary antibody (BD Biosciences \#555428). Cells were suspended in Hank's Balanced Salt Solution (HBSS; Gibco) with 2\% Heat Inactivated Calf Serum (HICS) added to a concentration of 1 million cells per $\mathrm{mL}$. Five $\mathrm{uL}$ of primary antibody was added per $\mathrm{mL}$ of cell suspension, and left to incubate on ice for 20 minutes. Cells were then pelleted down and re-suspended in HBSS to a concentration of 1 million cells per mL. Five $\mathrm{uL}$ of secondary antibody was added per $\mathrm{mL}$ of cell suspension for 20 minutes on ice. 4', 6diamidino-2-phenylindole (DAPI; BD Pharmingen) was used as a cell viability indicator. For NCAM expression, cell-sorting gates were established using an unstained control population in the allophycocyanin (APC) channel with excitation and emission wavelengths of 
approximately $650 \mathrm{~nm} / 660 \mathrm{~nm}$. For FSP and CD24 expression, cell-sorting gates were established using an unstained control population in the Phycoerythrin (PE) channel with excitation and emission wavelengths of approximately $565 \mathrm{~nm} / 578 \mathrm{~nm}$. Brachyury expression was detected using an antibody conjugated to fluorescein isothiocyanate (FITC; Millipore \#FCMAB302F). A cell suspension was fixed in $4 \%$ paraformaldehyde on ice for 10 minutes then permeabilized in methanol for 10 minutes at $-20^{\circ} \mathrm{C}$. Cells were resuspended in phosphate-buffered saline (PBS) and incubated with the antibody on ice for 30 minutes. Cells were then pelleted down and re-suspended in PBS with DAPI as a cell viability indicator. Cell sorting gates were established using an unstained control population in the FITC channel with excitation and emission wavelengths of approximately $495 \mathrm{~nm} / 521 \mathrm{~nm}$. Aldehyde dehydrogenase (ALDH) activity was detected using the ALDEFLUOR kit (StemCell Technologies). A single cell suspension in Aldefluor Assay Buffer (AAB) was incubated with ALDH substrate (BAAA, 5 mol/L per $1 \times 10^{6}$ cells) for 45 minutes at $37^{\circ} \mathrm{C}$. Concurrently; diethylaminobenzaldehyde (DEAB $50 \mathrm{mmol} / \mathrm{L}$ ) was added to a separate sample also containing BAAA for an ALDH-inhibited control. Samples were washed and resuspended in $\mathrm{AAB}$. Fluorescence-activated cell sorting gates were established using the inhibited control (DEAB) along the FITC channel.

\section{Immunofluorescence Staining}

Chordoma cells were plated onto collagen I treated chamber slides (BD Biosciences). Cells were fixed with $4 \%$ paraformaldehyde on ice for ten minutes, permeabilized with methanol at $-20^{\circ} \mathrm{C}$ for ten minutes, and incubated with either a Brachyury-FITC antibody (Millipore \#FCMAB302F) or CD24-PE antibody (BD Biosciences \#555428) for 30 minutes on ice. Samples were then coated with a DAPI-containing mountant (Molecular Probes) and left overnight. Immunofluorescence images were taken with an Olympus BX-51 upright light microscope at the University of Michigan Microscopy \& Image Analysis Laboratory.

\section{Spheroid Growth}

Chordoma cells were suspended in medium prepared as above but absent of FBS and plated on ultra-low attachment plates (Corning) to promote spheroid growth as previously described. Once clusters of cells, dubbed chordospheres, were observed for four days they were processed and prepared for flow cytometry to determine ALDH activity as described above.

\section{Luciferase Transduction}

UM-Chor1 was transduced at the University of Michigan Vector Core with recombinant human immunodeficiency virus (rHIV) with a luciferase reporter. A lentiviral vector containing a pLentilox backbone and a cytomegalovirus promoter was used to provide stable integration in permanent cell lines rather than the transient transfection typically provided by adenovirus. Polybrene was added to increase efficiency of the transduction. Successful gene delivery was confirmed via green fluorescent protein (GFP) visualization in a side-by-side transduction of the rHIV-GFP vector under identical conditions. 


\section{Parasacral Injections}

One million UM-Chor 1 cells were suspended in $100 \mathrm{ul}$ of media and $100 \mathrm{ul}$ of matrigel matrix (Corning). The suspensions were injected parasacrally into three NOD/SCID mice and imaged at 1-week intervals.

\section{Bioluminescence Imaging}

All animals treated with UM-Chor1-Luc injections were imaged with the Xenogen IVIS-200 imaging system at the University of Michigan Center for Molecular Imaging. Treated mice were given intraperitoneal injections of $100 \mathrm{uL}$ luciferin at a concentration of $40 \mathrm{mg} / \mathrm{mL}$ and allowed to sit for 10 minutes before being anesthetized with isofluorane and imaged.

\section{Results Case Report}

A 64-year-old gentleman initially presented with headaches and progressively diminishing vision in the left half of his visual field. Magnetic resonance imaging (MRI) revealed a $2 \mathrm{~cm}$ x $2 \mathrm{~cm}$ sellar and suprasellar lesion with solid, cystic, and hemorrhagic components. It extended along the clivus, prepontine cistern, and into the bilateral cavernous, sphenoid, and right posterior ethmoid sinuses. The optic chiasm and third ventricle were upwardly displaced. He underwent an uncomplicated transnasal transsphenoidal resection of the lesion, and pathology demonstrated a pituitary adenoma that stained positively for adrenocorticotropic hormone (ACTH). Clinically, he did not have signs of Cushing disease. He recovered well from his operation, although a follow-up MRI showed a small amount of residual mass in the posterior sella and within the cavernous sinus. He recovered well postoperatively until 4 months later, when he presented to the emergency department with diplopia, and was found to have a partial right-sided oculomotor nerve palsy. Imaging showed some enlargement of the cavernous sinus lesion, and he thus underwent fractionated radiation therapy for a total dose of $4500 \mathrm{cGy}$. Fifteen months post-operatively, he again presented to the emergency department with severe headaches and decreased visual acuity. An MRI showed significant enlargement of the suprasellar lesion, and he was taken emergently for decompression of what was later diagnosed histologically as an acute hematoma, felt to be in part attributable to warfarin, taken for atrial fibrillation. He tolerated this operation well, and was followed with serial imaging.

Approximately 2 years following the initial operation, the patient returned to the clinic with complaints of right-sided facial numbness. In addition to worsening of his right oculomotor nerve palsy, his physical examination showed diminished visual acuity, bitemporal hemianopia, and diminished sensation of the right face in the V2 distribution. Imaging showed further progression of his mass, and it was recommended that he begin temozolamide and undergo resection via the expanded endoscopic endonasal approach. Tissue from this operation was analyzed and, surprisingly, revealed a pituitary adenoma with superimposed lobules of vacuolated cells separated by fibrous septae. Additionally, there was invasion of the sinonasal mucosa and bone. Tissue stains were strongly positive for cytokeratin, S-100, and epithelial membrane antigen (EMA). The final pathologic diagnosis revealed chordoma in a background of pituitary adenoma. The patient recovered well 
following this operation, and was again evaluated by radiation oncologists. Intensitymodulated radiation therapy was prescribed to a total dose of $7400 \mathrm{cGy}$ in $180 \mathrm{cGy}$ fractions. Radiation was tolerated well, though unfortunately, his most recent MRI showed extensive anterior extension of his lesion into the posterior ethmoids. He enrolled in a clinical trial including imatinib and panobinostat. However, he presented with the acute onset of left ophthalmoparesis, and thus he was taken for urgent decompression and staged resection via the expanded endoscopic endonasal approach. He regained oculomotor function and tolerated this operation without complication. Histopathologic analysis again confirmed the diagnosis of chordoma.

\section{Cell Line Establishment}

The primary disease shows phenotypic characteristics of a classical chordoma- physaliferous cells with small, round nuclei (Figure 1A). Small pieces of chordoma tumor tissue were grown in flasks treated with Collagen I to promote adhesion (Figure 1B). When fibroblast overgrowth became a concern, cells were sorted by flow cytometry to separate the two cell types. Conventional methods of fibroblast removal involving partial trypsinizations were ineffective due to the detachment of chordoma cells at the same time as fibroblasts at low concentrations of trypsin. Fibroblast surface protein (FSP) and neural cell adhesion molecule (NCAM) were used to separate and sort the fibroblast and chordoma populations, respectively (Figure 2). Other chordoma markers were tested, but epithelial membrane antigen (EMA), epithelial cell adhesion molecule (EpCAM), and CD24 were found not to be optimum due to weaker staining or marker presence on the fibroblasts (data not shown). After ten passages of purified chordoma cells, adhesion in typical tissue-culture flasks was confirmed and cells were grown until enough doublings occurred to suggest immortality (Figure 1C). Genotyping results of the cells were unique when compared to all previously established chordoma cell lines and head and neck cell lines catalogued in our laboratory as tested by a short tandem repeat (STR) analysis, confirming UM-Chor1 as a novel cell line.

\section{Chordoma Characterization}

UM-Chor1 was evaluated for brachyury and CD24 expression by immunofluorescence staining (Figure 3A). The line was compared to previously established chordoma lines $\mathrm{UCH} 1$ and $\mathrm{UCH} 2$. Nuclear localization of the transcription factor brachyury was seen and transcription of brachyury and CD24 was confirmed. Intracellular brachyury presence was also confirmed by flow cytometry (Figure 3B).

\section{ALDH1}

Identification of an $\mathrm{ALDH}^{\mathrm{High}}$ chordoma population was attempted by measurement of a cell population with increased ALDH activity via the Aldefluor assay. UCH1, UCH2, and UM-Chor1 all had negligible populations of cells that had higher ALDH activity than the rest of the population (Figure 4). Spheroid growth in low attachment plates of UM-Chor1 resulted in small aggregates of cell clusters that, when analyzed for ALDH activity, showed no increase in a population of cells with higher ALDH activity (Figure 5). 


\section{In vivo Model}

UM-Chor 1 cells were successfully transduced with luciferase and $1.0 \times 10^{6}$ cells were injected parasacrally into three NOD/SCID mice and measured over a five-week period, showing slow growth of the xenograft via bioluminescence (Figure 6). The resulting xenografts exhibited classical chordoma characteristics similar to the primary tumor when stained for intranuclear brachyury.

\section{Discussion}

We discuss in detail the in vitro establishment and initiation of an in vivo model for the first chordoma cell line derived from the clivus. Prior treatment may impact genetic expression in cell lines established from surgery, but we deemed it important to attempt cell line establishment due to the absence of a clival chordoma cell line available for research. Primary tissue was able to be processed and expanded in culture and then purified using a two-antibody sorting method that our laboratory had previously developed to establish squamous cell carcinomas of the head and neck ${ }^{30}$. NCAM was selected as a surface chordoma marker present on UM-Chor1 cells and absent on fibroblasts, but is not a definitive marker for chordoma. A 2001 study revealed NCAM expression in 14 out of 16 chordoma samples, with high preservation of NCAM expression in the two skull base chordomas tested ${ }^{27}$. In this particular case, NCAM was a good marker for the skull basederived UM-Chor1 cell line. Removal of fibroblasts from the initial cultures is vital for successful chordoma cell propagation due to the stark difference in division rates. The doubling time of fibroblasts can be less than 24 hours, in contrast to that of chordoma cells which can be as high as seven days ${ }^{20,25}$. UM-Chor1 has an in vitro doubling time of approximately five days, making immediate removal of the more quickly dividing fibroblasts important. Thorough establishment of slow-growing chordoma cell lines does require an increased initial investment of time compared to cell lines derived from other solid tumors. The division rates of sacral chordoma cell line UCH1 was decreased by isolation of a fastergrowing subpopulation, and we suspect this may be possible for UM-Chor1 in the future ${ }^{20}$.

As recently as 2010, there were seven chordoma lines described in the literature, but which lacked characterization ${ }^{6}$. Thorough investigation eliminated all but two lines, UCH1 and $\mathrm{UCH} 2$, as valid chordoma cell lines. The discovery of brachyury as a prime diagnostic marker has improved the validation process for potential chordoma cell lines, with over $90 \%$ of chordomas expressing the transcription factor ${ }^{18}$. Chromosomal aberrations resulting in copy number gain of brachyury is present in both sporadic and familial disease, and knockdown of the gene induces apoptosis and arrests cell growth in vitro ${ }^{32,40}$. In other cancers, brachyury has been shown to be involved in epithelial to mesenchymal transition, and overexpression leads to down-regulated expression of E-cadherin and induction of metastasis ${ }^{12}$. UM-Chor1 exhibited intranuclear localization of brachyury as well as cytoplasmic mislocalization. These observations were independently verified by the Chordoma Foundation, who also measured it as having a nearly six-fold increase in expression when compared to UCH2.

CD24, a heat stable antigen, is another surface marker expressed in many tumor types $^{22,26,34,35}$. CD24 is involved in cell adhesion and metastasis, and increases 
proliferation and affinity of tumor cells to collagen, fibronectin, and lamin ${ }^{23}$. CD24 has been shown to have variable glycosylation, resulting in a diverse set of functions in different cell types ${ }^{13,29}$. While high expression of CD24 enhances tumor progression in most cancers studied, intracellular expression in pancreatic cancer inhibited cell invasion and metastasis ${ }^{36}$. CD24 was discovered to be a marker for nucleus pulposus cells located in the inner core of the vertebral disc, and used to distinguish chordoma from chondrosarcoma ${ }^{7,15}$. The function of CD24 in chordoma is not yet understood, but can be used as a chordoma marker to validate potential new cell lines. UM-Chor1 expressed CD24 on the cellular surface, and this was independently verified by the Chordoma Foundation, with an expression nearly threefold that of $\mathrm{UCH} 2$.

In an effort to isolate a cancer initiating subpopulation in UM-Chor1, we looked at ALDH1 activity. Our laboratory first described ALDH ${ }^{\text {High }}$ cancer stem cells in head and neck squamous cell carcinomas in 2010, and have consistently isolated an $\mathrm{ALDH}^{\mathrm{High}}$ population in each new carcinoma cell line established at the University of Michigan since that time ${ }^{10}$. We tested UCH1, UCH2, and UM-Chor1 for enzymatic activity of ALDH1 but did not find a discernible population of increased activity, with $.48 \%, .37 \%$, and $.17 \%$, respectively. Other groups have found similar numbers, with .35\% isolated from UCH1 and .30\% isolated from MUG-Chor $1^{33}$. To compare, nearly $6.83 \%$ of our control fibroblasts exhibited increased ALDH1 activity, and an evaluation of twenty head and neck cell lines stored in our laboratory yielded an average $\mathrm{ALDH}^{\mathrm{High}}$ population of $7.19 \%$ (data not yet published). Perhaps more importantly, the ALDH ${ }^{\text {High }}$ cell populations in non-chordoma cell lines were readily apparent in flow cytometry plots, separated by at least a ten-fold increase in bioluminescence caused by the enzymatic reaction with the Aldefluor substrate. Chordoma cell lines did not exhibit such separation, and the low percentages recorded cannot be ruled out as background luminescence. UM-Chor1 cells were successfully grown as spheroids in serum-free culture, which enhances the stem cell population in other cancer lines. Upon reanalysis, the $\mathrm{ALDH}^{\mathrm{High}}$ population of the chordospheres rose to just $.24 \%$. It is possible that ALDH is not as potent of a marker in chordomas as other cancers, but with the small number of cell lines currently available, it should not be discounted entirely.

Other groups have reported successful xenograft passaging of primary chordoma tissue in mice, which may have a higher chance of propagating chordoma cells than growing the primary in culture $5,11,38$. While we prefer to establish cell lines in vitro, eliminating possible complications of an animal host, the benefits of developing an animal model for newly established cell lines allows for vital research to be conducted before clinical trials may be proposed. To this end, we performed flank injections of $1.0 \times 10^{6}$ cells from UMChor1 into the flanks of Nude mice. No growth was observed after six months, so the more immunodeficient NOD/SCID strain was then utilized. At this point, UM-Chor1 had been successfully transduced with luciferase, allowing in vivo imaging of tumor growth. Cells were injected parasacrally as suggested by the literature, and initiation of tumors was seen at the injection sites in each of the three mice tested. Bioluminescent imaging revealed slow tumor growth over the duration of five weeks, with the UM-Chor1 xenografts resembling the patient disease histologically. The availability of a clival chordoma cell line that is capable of successful growth in an animal model will be a valuable tool to future chordoma research. 


\section{Conclusions}

UM-Chor1 is the first established chordoma cell line derived from classical chordoma of the clivus, or skull base. The cells exhibit a physaliferous chordoma phenotype, and express the diagnostic chordoma markers brachyury and CD24. The cell line was validated independently by the Chordoma Foundation and stored in their cell line repository and is available for research through the foundation and the ATCC. We have been able to successfully transduce UM-Chor1 with a lentiviral vector as well as grow it in a NOD/SCID mouse model. There are only a handful of validated chordoma cell lines worldwide, all derived from the sacrum, and the addition of a clival line adds a valuable second disease site to study. We would like to acknowledge the continued guidance and support from the Chordoma Foundation and the assistance of the University of Michigan Flow Cytometry Core and the University of Michigan Vector Core.

\section{References}

1. Abdullah LN, Chow EK-H. Mechanisms of chemoresistance in cancer stem cells. Clinical and Translational Medicine. 2013; 2:1-9. [PubMed: 23369533]

2. Aydemir E, Bayrak OF, Sahin F, Atalay B, Kose GT, Ozen M, et al. Characterization of cancer stemlike cells in chordoma. J Neurosurg. 2012; 116:810-820. [PubMed: 22283189]

3. Barresi V, Ieni A, Branca G, Tuccari G. Brachyury: A Diagnostic Marker for the Differential Diagnosis of Chordoma and Hemangioblastoma versus Neoplastic Histological Mimickers. Disease Markers. 2014; 2014:7.

4. Bergh P, Kindblom LG, Gunterberg B, Remotti F, Ryd W, Meis-Kindblom JM. Prognostic factors in chordoma of the sacrum and mobile spine: a study of 39 patients. Cancer. 2000; 88:2122-2134. [PubMed: 10813725]

5. Bozzi F, Manenti G, Conca E, Stacchiotti S, Messina A, Dagrada G, et al. Development of transplantable human chordoma xenograft for preclinical assessment of novel therapeutic strategies. Neuro-Oncology. 2013

6. Bruderlein S, Sommer JB, Meltzer PS, Li S, Osada T, Ng D, et al. Molecular characterization of putative chordoma cell lines. Sarcoma. 2010; 2010:630129. [PubMed: 21253487]

7. Chen Y-F, Zhang Y-Z, Zhang W-L, Luan G-N, Liu Z-H, Gao Y, et al. Insights into the Hallmarks of Human Nucleus Pulposus Cells with Particular Reference to Cell Viability, Phagocytic Potential and Long Process Formation. International Journal of Medical Sciences. 2013; 10:1805-1816. [PubMed: 24324357]

8. Cho HY, Lee M, Takei H, Dancer J, Ro JY, Zhai QJ. Immunohistochemical comparison of chordoma with chondrosarcoma, myxopapillary ependymoma, and chordoid meningioma. Appl Immunohistochem Mol Morphol. 2009; 17:131-138. [PubMed: 19521276]

9. Chugh R, Tawbi H, Lucas DR, Biermann JS, Schuetze SM, Baker LH. Chordoma: the nonsarcoma primary bone tumor. Oncologist. 2007; 12:1344-1350. [PubMed: 18055855]

10. Clay MR, Tabor M, Owen JH, Carey TE, Bradford CR, Wolf GT, et al. Single-marker identification of head and neck squamous cell carcinoma cancer stem cells with aldehyde dehydrogenase. Head Neck. 2010; 32:1195-1201. [PubMed: 20073073]

11. Davies JM, Robinson AE, Cowdrey C, Mummaneni PV, Ducker GS, Shokat KM, et al. Generation of a patient-derived chordoma xenograft and characterization of the phosphoproteome in a recurrent chordoma. J Neurosurg. 2014; 120:331-336. [PubMed: 24286145]

12. Du R, Wu S, Lv X, Fang H, Wu S, Kang J. Overexpression of brachyury contributes to tumor metastasis by inducing epithelial-mesenchymal transition in hepatocellular carcinoma. Journal of Experimental \& Clinical Cancer Research. 2014; 33:1-11. [PubMed: 24383517]

13. Fang X, Zheng P, Tang J, Liu Y. CD24: from A to Z. Cell Mol Immunol. 2010; 7:100-103. [PubMed: 20154703] 
14. Ferraresi V, Nuzzo C, Zoccali C, Marandino F, Vidiri A, Salducca N, et al. Chordoma: clinical characteristics, management and prognosis of a case series of 25 patients. BMC Cancer. 2010; 10:1-10. [PubMed: 20047689]

15. Fujita N, Miyamoto T, Imai J, Hosogane N, Suzuki T, Yagi M, et al. CD24 is expressed specifically in the nucleus pulposus of intervertebral discs. Biochem Biophys Res Commun. 2005; 338:18901896. [PubMed: 16288985]

16. Ginestier C, Hur MH, Charafe-Jauffret E, Monville F, Dutcher J, Brown M, et al. ALDH1 is a marker of normal and malignant human mammary stem cells and a predictor of poor clinical outcome. Cell Stem Cell. 2007; 1

17. Hsu W, Mohyeldin A, Shah SR, ap Rhys CM, Johnson LF, Sedora-Roman NI, et al. Generation of chordoma cell line JHC7 and the identification of Brachyury as a novel molecular target. J Neurosurg. 2011; 115:760-769. [PubMed: 21699479]

18. Jambhekar NA, Rekhi B, Thorat K, Dikshit R, Agrawal M, Puri A. Revisiting chordoma with brachyury, a "new age" marker: analysis of a validation study on 51 cases. Arch Pathol Lab Med. 2010; 134:1181-1187. [PubMed: 20670140]

19. Jemal A, Siegel R, Ward E, Murray T, Xu J, Thun MJ. Cancer statistics, 2007. CA Cancer J Clin. 2007; 57:43-66. [PubMed: 17237035]

20. Kato TA, Tsuda A, Uesaka M, Fujimori A, Kamada T, Tsujii H, et al. In vitro characterization of cells derived from chordoma cell line U-CH1 following treatment with X-rays, heavy ions and chemotherapeutic drugs. Radiat Oncol. 2011; 6:116. [PubMed: 21914223]

21. Kelley MJ, Shi J, Ballew B, Hyland PL, Li WQ, Rotunno M, et al. Characterization of T gene sequence variants and germline duplications in familial and sporadic chordoma. Hum Genet. 2014; 133:1289-1297. [PubMed: 24990759]

22. Kim KH, Choi JS, Kim JM, Choi YL, Shin YK, Lee HC, et al. Enhanced CD24 expression in endometrial carcinoma and its expression pattern in normal and hyperplastic endometrium. Histol Histopathol. 2009; 24:309-316. [PubMed: 19130400]

23. Lee JH, Kim SH, Lee ES, Kim YS. CD24 overexpression in cancer development and progression: a meta-analysis. Oncol Rep. 2009; 22:1149-1156. [PubMed: 19787233]

24. Lohberger B, Rinner B, Stuendl N, Absenger M, Liegl-Atzwanger B, Walzer SM, et al. Aldehyde dehydrogenase 1, a potential marker for cancer stem cells in human sarcoma. PLoS One. 2012; 7:e43664. [PubMed: 22928012]

25. Mio T, Nagai S, Kitaichi M, Kawatani A, Izumi T. Proliferative characteristics of fibroblast lines derived from open lung biopsy specimens of patients with IPF (UIP). Chest. 1992; 102:832-837. [PubMed: 1516411]

26. Nagy B, Szendroi A, Romics I. Overexpression of CD24, c-myc and phospholipase 2A in prostate cancer tissue samples obtained by needle biopsy. Pathol Oncol Res. 2009; 15:279-283. [PubMed: 18752058]

27. Naka T, Oda Y, Iwamoto Y, Shinohara N, Chuman H, Fukui M, et al. Immunohistochemical analysis of E-cadherin, alpha-catenin, beta-catenin, gamma-catenin, and neural cell adhesion molecule (NCAM) in chordoma. J Clin Pathol. 2001; 54:945-950. [PubMed: 11729215]

28. Oakley GJ, Fuhrer K, Seethala RR. Brachyury, SOX-9, and podoplanin, new markers in the skull base chordoma vs chondrosarcoma differential: a tissue microarray-based comparative analysis. Mod Pathol. 2008; 21:1461-1469. [PubMed: 18820665]

29. Ohl C, Albach C, Altevogt P, Schmitz B. N-glycosylation patterns of HSA/CD24 from different cell lines and brain homogenates: a comparison. Biochimie. 2003; 85:565-573. [PubMed: 12829373]

30. Owen JH, Graham MP, Chinn SB, Darr OF, Chepeha DB, Wolf GT, et al. Novel method of cell line establishment utilizing fluorescence-activated cell sorting resulting in 6 new head and neck squamous cell carcinoma lines. Head Neck. 2015

31. Park L, Delaney TF, Liebsch NJ, Hornicek FJ, Goldberg S, Mankin H, et al. Sacral chordomas: Impact of high-dose proton/photon-beam radiation therapy combined with or without surgery for primary versus recurrent tumor. Int J Radiat Oncol Biol Phys. 2006; 65:1514-1521. [PubMed: 16757128] 
32. Presneau N, Shalaby A, Ye H, Pillay N, Halai D, Idowu B, et al. Role of the transcription factor T (brachyury) in the pathogenesis of sporadic chordoma: a genetic and functional-based study. $\mathrm{J}$ Pathol. 2011; 223:327-335. [PubMed: 21171078]

33. Rinner B, Froehlich EV, Buerger K, Knausz H, Lohberger B, Scheipl S, et al. Establishment and detailed functional and molecular genetic characterisation of a novel sacral chordoma cell line, MUG-Chor1. Int J Oncol. 2012; 40:443-451. [PubMed: 22002331]

34. Sagiv E, Arber N. The novel oncogene CD24 and its arising role in the carcinogenesis of the GI tract: from research to therapy. Expert Rev Gastroenterol Hepatol. 2008; 2:125-133. [PubMed: 19072375]

35. Sano A, Kato H, Sakurai S, Sakai M, Tanaka N, Inose T, et al. CD24 expression is a novel prognostic factor in esophageal squamous cell carcinoma. Ann Surg Oncol. 2009; 16:506-514. [PubMed: 19050962]

36. Taniuchi K, Nishimori I, Hollingsworth MA. Intracellular CD24 Inhibits Cell Invasion by Posttranscriptional Regulation of BART through Interaction with G3BP. Cancer Research. 2011; 71:895-905. [PubMed: 21266361]

37. Tauziède-Espariat A, Bresson D, Polivka M, Bouazza S, Labrousse F, Aronica E, et al. Prognostic and Therapeutic Markers in Chordomas: A Study of 287 Tumors. Journal of Neuropathology \& Experimental Neurology. 2016

38. Trucco MM, Awad O, Wilky BA, Goldstein SD, Huang R, Walker RL, et al. A novel chordoma xenograft allows in vivo drug testing and reveals the importance of NF-kappaB signaling in chordoma biology. PLoS One. 2013; 8:e79950. [PubMed: 24223206]

39. Vinogradov S, Wei X. Cancer stem cells and drug resistance: the potential of nanomedicine. Nanomedicine (Lond). 2012; 7:597-615. [PubMed: 22471722]

40. Yang XR, Ng D, Alcorta DA, Liebsch NJ, Sheridan E, Li S, et al. T (brachyury) gene duplication confers major susceptibility to familial chordoma. Nat Genet. 2009; 41:1176-1178. [PubMed: 19801981] 

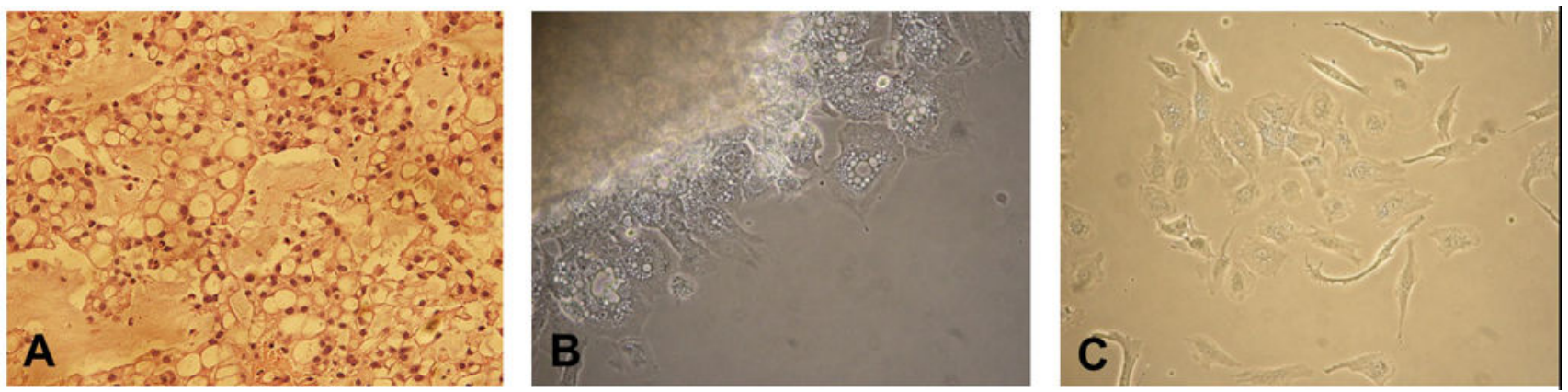

Figure 1.

A) The primary clival chordoma exhibited phenotypic characteristics of classical chordoma. B) Small pieces of tumor tissue adhered to a flask coated with collagen I and chordoma cells grew from it. C) UM-Chor1 at passage 35. 

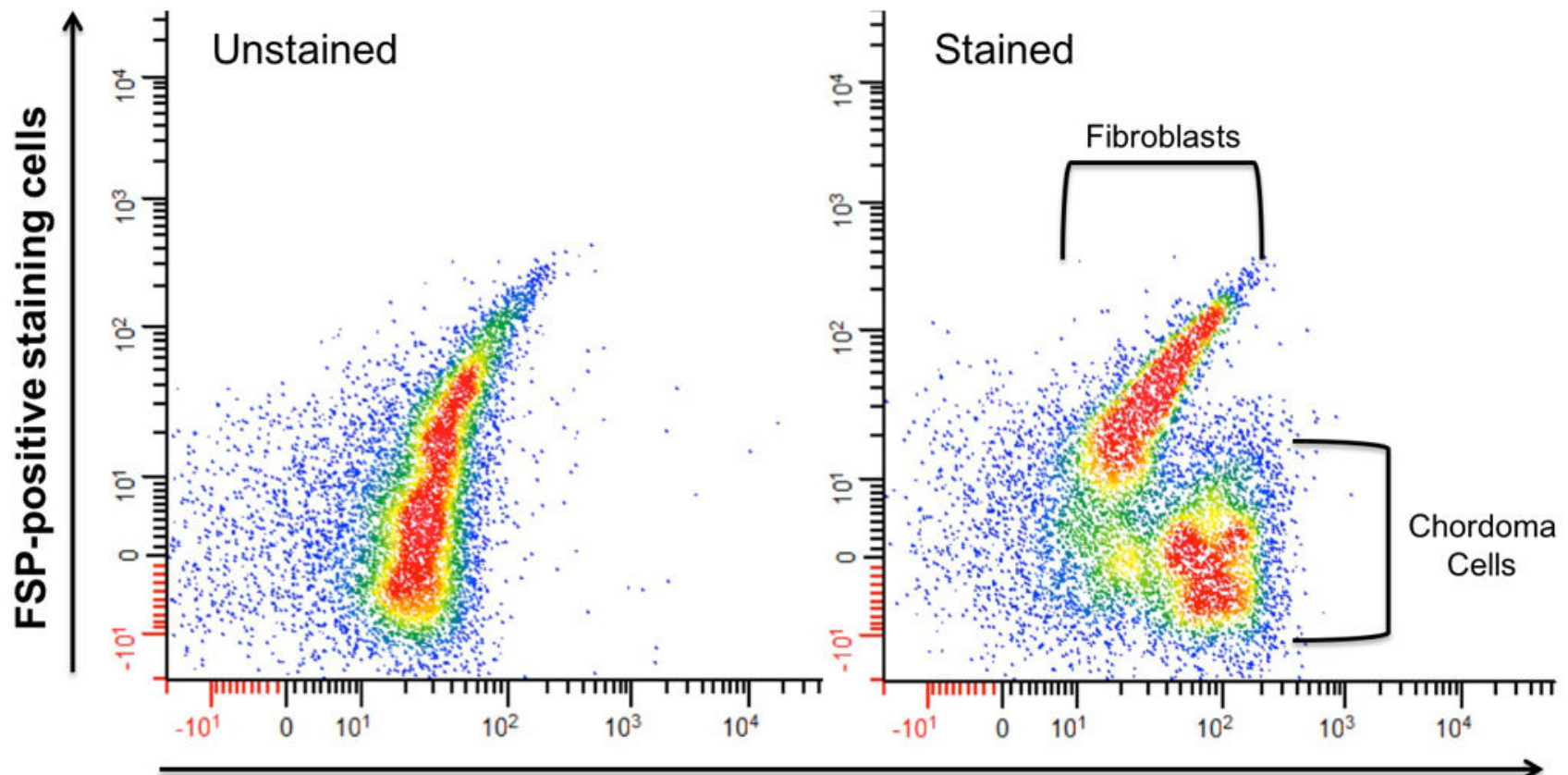

NCAM-positive staining cells

Figure 2.

A single cell suspension of chordoma cells and fibroblasts was separated by flow cytometry. The unstained cell population (left) was used as a control for the cell population stained with antibody markers for fibroblasts and chordomas (right). 
A DAPI Brachyury-FITC CD24-PE Merge

$\mathrm{UCH} 1$
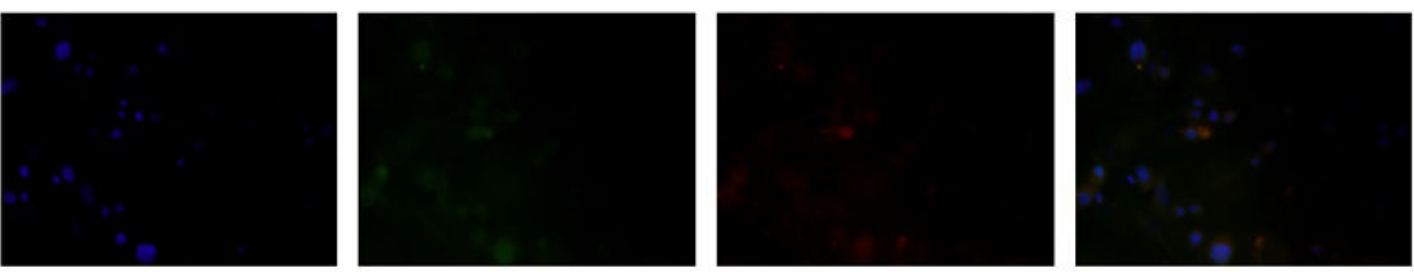

$\mathrm{UCH} 2$
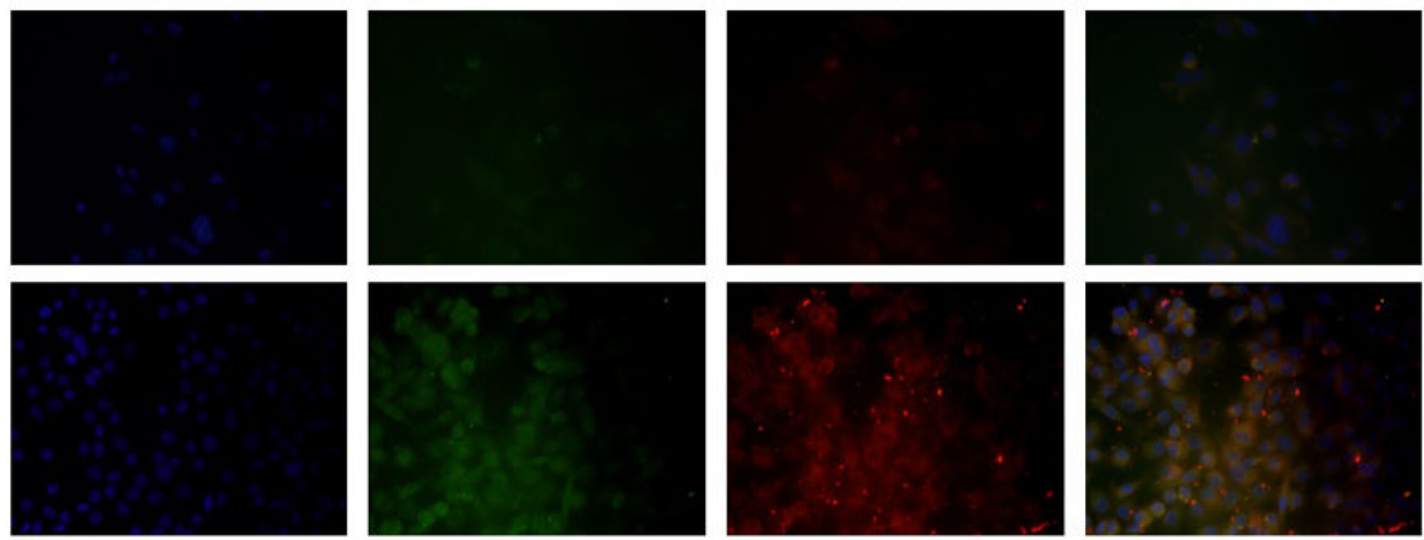

B

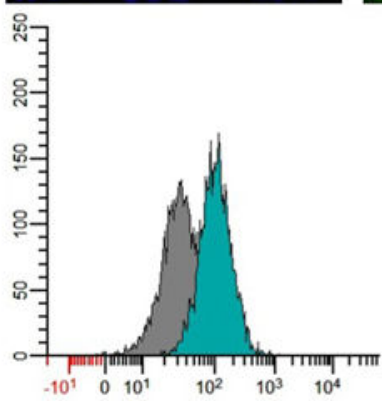

Figure 3.

A) UCH1, UCH2, and UM-Chor1 were stained for DAPI, Brachyury, and CD24. Intranuclear staining of brachyury was strong in UM-Chor1. B) Brachyury was also confirmed in UM-Chor1 by flow cytometry, compared to an isotype control antibody. 
$\mathrm{UCH} 1$
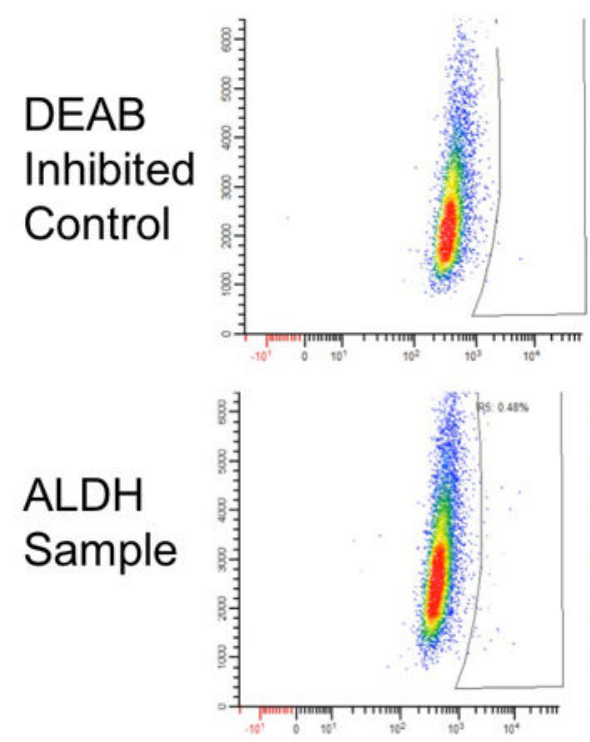

$\mathrm{UCH} 2$
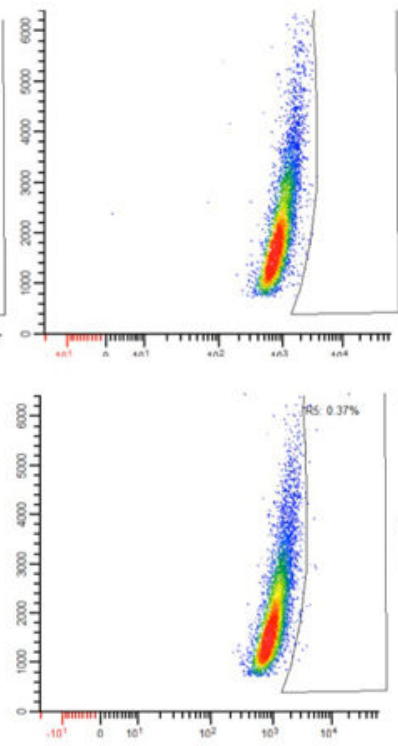

UM-Chor1

Fibroblasts
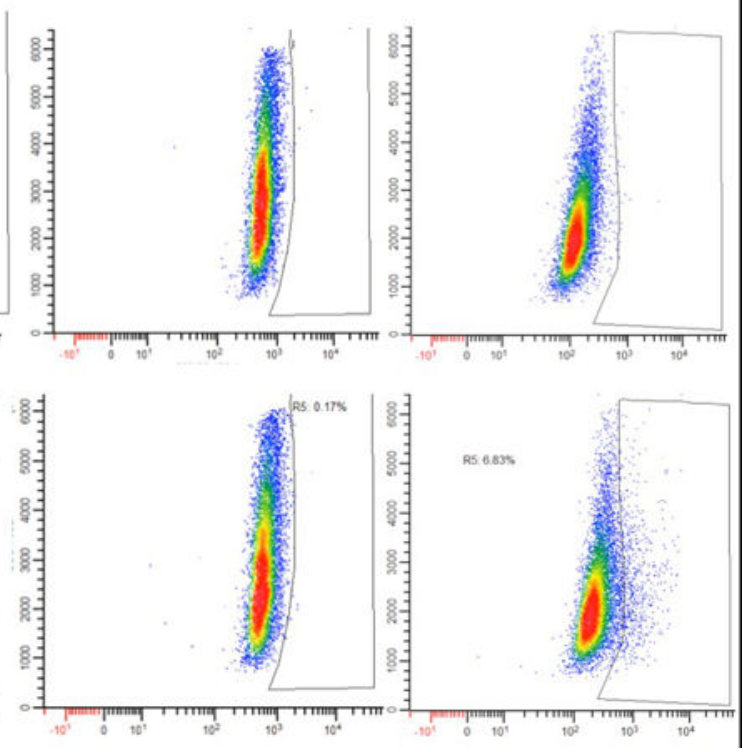

Figure 4.

UCH1, UCH2, UM-Chor1 and fibroblasts from a head and neck patient were analyzed for increased ALDH1 activity by the Aldefluor assay. When compared with a DEAB-inhibited control, UCH1, UCH2, UM-Chor1 registered $\mathrm{ALDH}^{\text {high }}$ populations of $.48 \%, .37 \%$, and . $17 \%$, respectively. In contrasts, the fibroblasts measured an $\mathrm{ALDH}^{\text {high }}$ population of $6.83 \%$. 

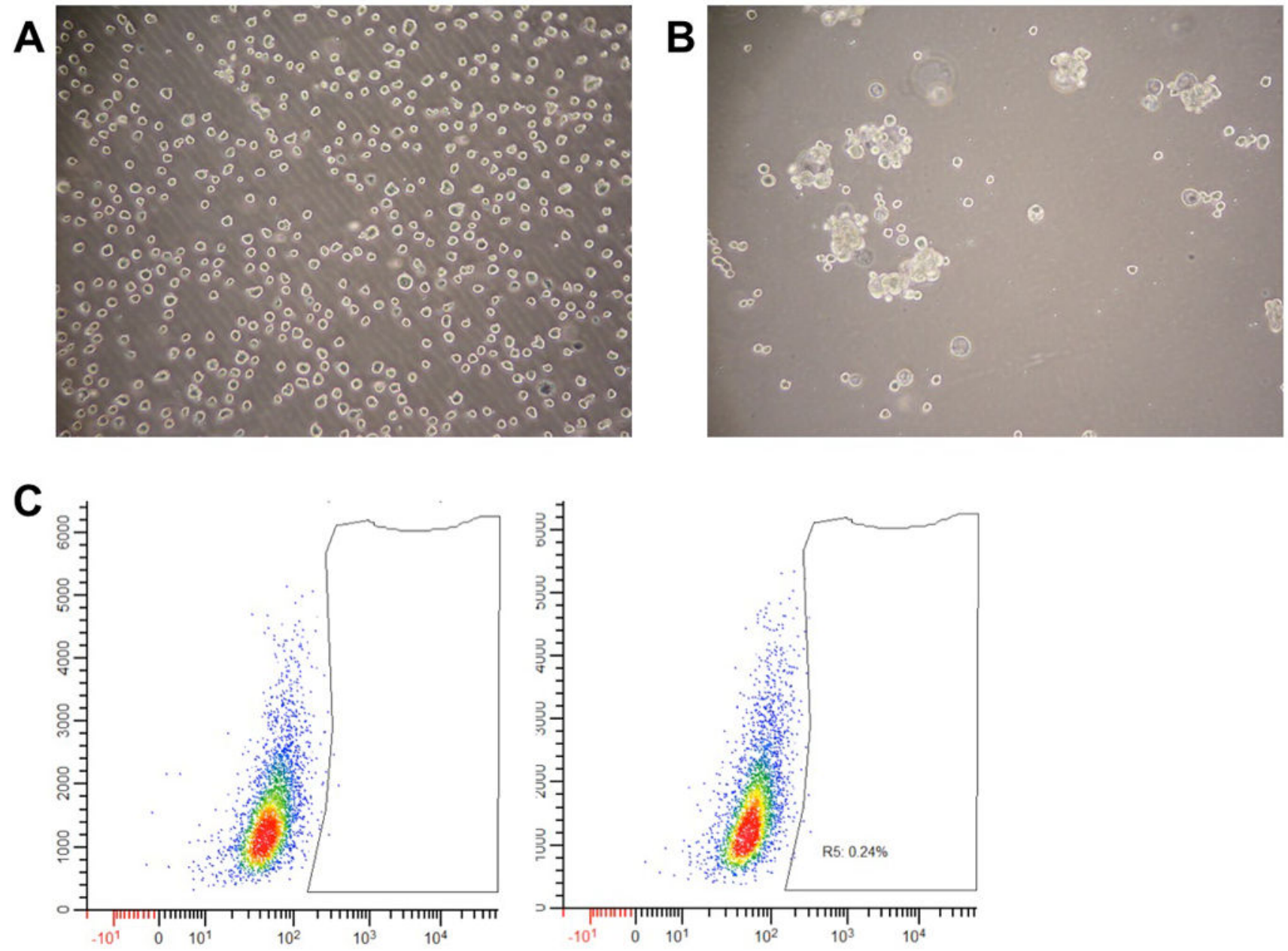

\section{DEAB Inhibited Control}

ALDH Sample

Figure 5.

A) UM-Chor1 cells were plated in a serum-free, low-attachment plate. B) After four days, small clusters of chordospheres were seen. C) Analyzing these chordospheres for ALDH1 against an inhibited control resulted in an $\mathrm{ALDH}^{\text {high }}$ population of .24\%. 


\section{A}

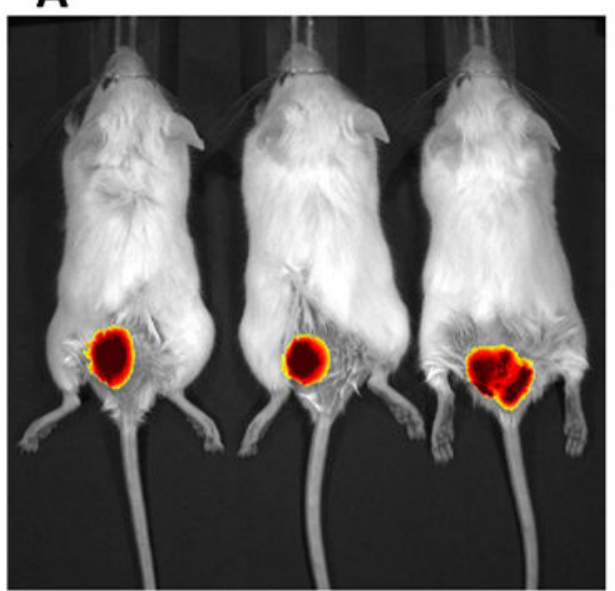

C

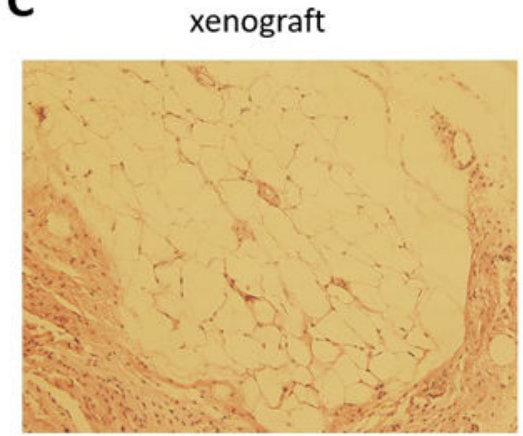

B

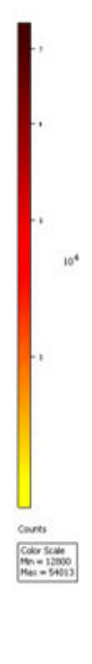

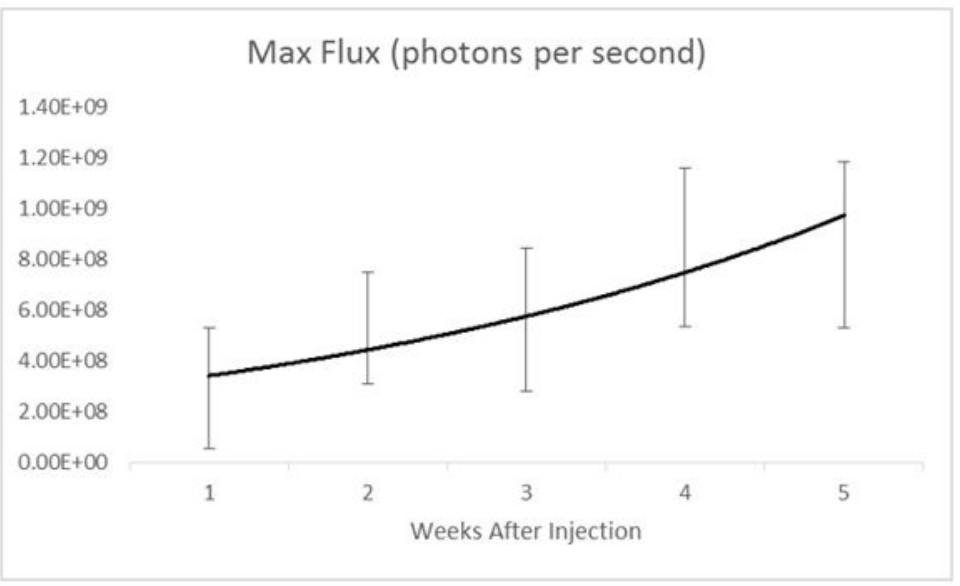

xenograft

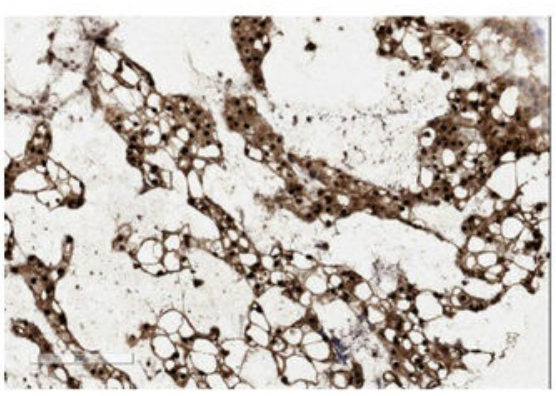

primary

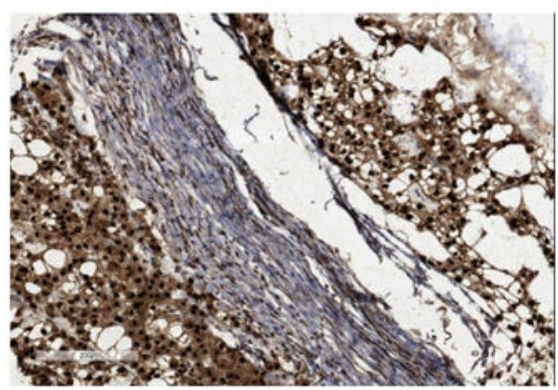

Figure 6.

A) UM-Chor 1 was successfully transduced with luciferase and $1.0 \times 10^{6}$ cells were injected parasacrally into three NOD/SCID mice. B) Tumor growth was measured over five weeks by bioluminescence. C) The xenograft resembled the original primary tumor when stained for intranuclear brachyury. 